\title{
ELEVATED VASCULAR ENDOTHELIAL GROWTH FACTOR (VEGF) LEVELS IN THE BLOOD SERUM OF DOGS WITH MALIGNANT NEOPLASMS OF THE ORAL CAVITY
}

\author{
Aleksandra SoBCZYŃSKA-RAK", Izabela POLKOWSKA and Piotr SILMANOWICZ \\ Department and Clinic of Animal Surgery, Faculty of Veterinary Medicine, \\ University of Life Sciences in Lublin, Lublin, Poland
}

(Received 12 April 2013; accepted 2 July 2013)

\begin{abstract}
Angiogenesis plays an essential role in the development of a neoplastic tumour by conditioning both its growth and the formation of metastases. The induction of blood vessel growth occurs under the influence of proangiogenic factors, among which Vascular Endothelial Growth Factor (VEGF) seems to be the most important. The aim of this research was to study the level of VEGF measured by ELISA in the serum of dogs with neoplasms of the oral cavity. The study material comprised samples of neoplastic tissue from 17 operated dogs and the serum of the examined animals as well as of dogs from the control group. The tissue samples were taken from dogs of different breeds, aged 6-14 years. The tumour type was determined in accordance with the applicable WHO classification. Blood samples taken from sick dogs and from animals of the control group were centrifuged, and immunoenzymatic labelling of VEGF was performed in the obtained serum using ELISA and R\&D system reagents (Quantikine Canine VEGF). All stages of VEGF labelling were performed according to the recommendation of the test manufacturer. The median of VEGF in the serum of the dogs with neoplasms of the oral cavity was $40.64 \mathrm{pg} / \mathrm{mL}$. The lowest value of $14.26 \mathrm{pg} / \mathrm{mL}$ was observed in the case of fibrosarcoma, and the highest value of $99.19 \mathrm{pg} / \mathrm{mL}$ in the case of squamous cell carcinoma. The VEGF median in the control group amounted to $11.14 \mathrm{pg} / \mathrm{mL}$ whereas the VEGF value in the groups of animals diagnosed with benign tumours ranged between 2.30 and $19.74 \mathrm{pg} / \mathrm{mL}$. Elevated VEGF in the blood serum, in comparison with the benign tumour group and the control group, was observed in all examined neoplasms of the oral cavity. It was suggested that overexpression of VEGF can have a prognostic value and is useful in the early detection of neoplasms.
\end{abstract} cavity

Key words: Vascular endothelial growth factor, VEGF, dog, tumour, oral

Cancerous hyperplasia depends to a large extent on neoangiogenesis, i.e. the process of creating a network of blood vessels in tumours. Numerous publi-

*Corresponding author; E-mail: olsob2@gmail.com; Phone: 0048 (81) 445-6193;

Fax: 0048 (81) 524-3808 
cations have dealt with angiogenesis and its role in many cancers of humans and animals. The increased density of blood vessels in comparison to normal tissues has been noted in cancers of the large intestine, uterus, breast, lungs, oral cavity as well as in cancers of the brain in humans. The number of newly created vessels has an influence on the progression and course of the disease. Moreover, the proper supply of blood to the tumour is conducive to its cells getting into the blood circulation and initiating the process of metastases (Bałan and Słotwiński, 2008; Michailidon et al., 2008).

The development of molecular biology and genetic engineering has contributed to our better knowledge and understanding of the phenomena related to vessel formation in tumours and the development of cancer. It has been shown that the induction of vessel growth is a process subject to a strict control by positive and negative regulators of angiogenesis (Bałan and Słotwiński, 2008; Szala, 2009). When this balance is upset, angiogenesis occurs. A lot of proteins have been described as proangiogenic factors, however, Vascular Endothelial Growth Factor (VEGF) poses to be potentially the most important factor involved in the process of tumour development (Dvorak et al., 1988; Ferrara, 1999; Bałan and Słotwiński, 2008). It is a glycosylated homodimer whose molecular weight is 46-48 $\mathrm{kDa}$. Through alternative mRNA maturation, $7 \mathrm{VEGF}$ isoforms are formed $\left[\mathrm{VEGF}_{121}, \mathrm{VEGF}_{145}, \mathrm{VEGF}_{148}, \mathrm{VEGF}_{165}, \mathrm{VEGF}_{183}, \mathrm{VEGF}_{189}, \mathrm{VEGF}_{206}\right.$ ] (Ferrara, 1999; Polverini, 2002; Roselli et al., 2003; Bałan and Słotwiński, 2008; Szala, 2009). The isoforms differ in the number of amino acids as well as in biochemical and biological properties. VEGF ${ }_{121}$ and $\mathrm{VEGF}_{165}$ are the most often examined isoforms. Depending on whether VEGF is anchored in the extracellular matrix (ECM), or if it is in a non-bound form, reactions of endothelial cells to the growth factor are different. Anchored VEGF (mainly $\mathrm{VEGF}_{165}$ ) is better recognised by receptors located on the processes of endothelial cells. $\mathrm{VEGF}_{121}$ is far less recognised. It is therefore believed that the vessel networks formed with the contribution of $\mathrm{VEGF}_{165}$ are denser than those formed with the contribution of VEGF $_{121}$ (Iruela-Arispe, 2008; Szala, 2009).

VEGF binds to three receptors that are located in endothelial cells and contain a tyrosine kinase domain: VEGFR-1 (Flt-1-fms-like tyrosine kinase-1), VEGFR-2 (KDR-kinase domain region) and VEGFR-3 (Dvorak, 2002; Takahashi and Shibuya, 2005). The presence of VEGF receptors was also observed in healthy lung, skin and bladder tissue in dogs (Uchida et al., 2008).

VEGF is secreted by many cells: T lymphocytes, macrophages, monocytes, fibroblasts, platelets after activation, and especially by neoplastic cells. It has been shown that angiogenesis is one of the ways by which neoplastic cells compensate for the lack of oxygen, and VEGF plays an important role at this stage (Dvorak et al., 1988; Szala, 2009). The most important factor participating in its expression is hypoxia, during which the hypoxia inducible factor HIF-1 is increased in the cells. A stimulation of VEGF expression can also occur under 
the influence of cytokines, interleukins and in consequence of mutation of some oncogenes, e.g. the p53 gene. VEGF is also the basis for the so-called angiogenic phenotype, i.e. the ability to produce and secrete proangiogenic factors by neoplastic cells (Szala, 2009).

VEGF results in mitogenesis of the vascular endothelial cells, causing their increased proliferation, migration and formation of vessels in a neoplastic tumour (Wergin and Kaser-Hotz, 2004; Sacewicz et al., 2009). Furthermore, this factor stimulates vascular permeability and shows autocrine activity, i.e. the protection of neoplastic cells against stress caused by chemotherapy and radiotherapy - the factor increases the survivability of neoplastic cells (Volk et al., 2008). Moreover, VEGF blocks the maturation and differentiation of dendritic cells, thus significantly weakening the immunological response (Wasik-Szczepanek and Koczkodaj, 2008).

Elevated serum VEGF levels have also been observed in human tumours. Studies have also been conducted into VEGF levels in the serum of animals diagnosed with e.g. skin and subcutaneous tissue cancer as well as mammary gland cancer. It has been demonstrated that, in such cases, VEGF overexpression can indicate a malignant course of the disease and a higher potential for metastasis (Kato et al., 2007; Sobczyńska-Rak, 2012).

The increased level of VEGF often correlates with angiogenesis. The overexpression of VEGF has also been confirmed in dogs diagnosed with oral melanomas as well as skin and subcutaneous tissue cancer. It has been demonstrated that VEGF level was significantly higher in melanomas than in benign tumours or in the serum of healthy dogs (Rawlings et al., 2003; Taylor et al., 2007; Sobczyńska-Rak et al., 2009; Smedley et al., 2011).

The aim of this research was to study the level of VEGF measured by ELISA in the serum of dogs with neoplasms of the oral cavity.

\section{Materials and methods}

The materials used in the study comprised samples of neoplastic tissue from 17 operated dogs and the serum of the examined animals as well as of dogs from the control group.

The animals were subjected to surgery at the Department and Clinic of Animal Surgery of the University of Life Sciences in Lublin after being diagnosed with neoplastic tumours occurring in their gums. Tissue samples were taken from the aforementioned 17 dogs of different breeds, aged 6-14 years (Table 1).

In the affected dogs, thoracic radiographic examinations were carried out to confirm or exclude metastasis. The level of VEGF in the serum of affected animals and in dogs of the control group was determined. 
Table 1. Results of histopathological diagnosis and immunoenzymatic examination in the test group

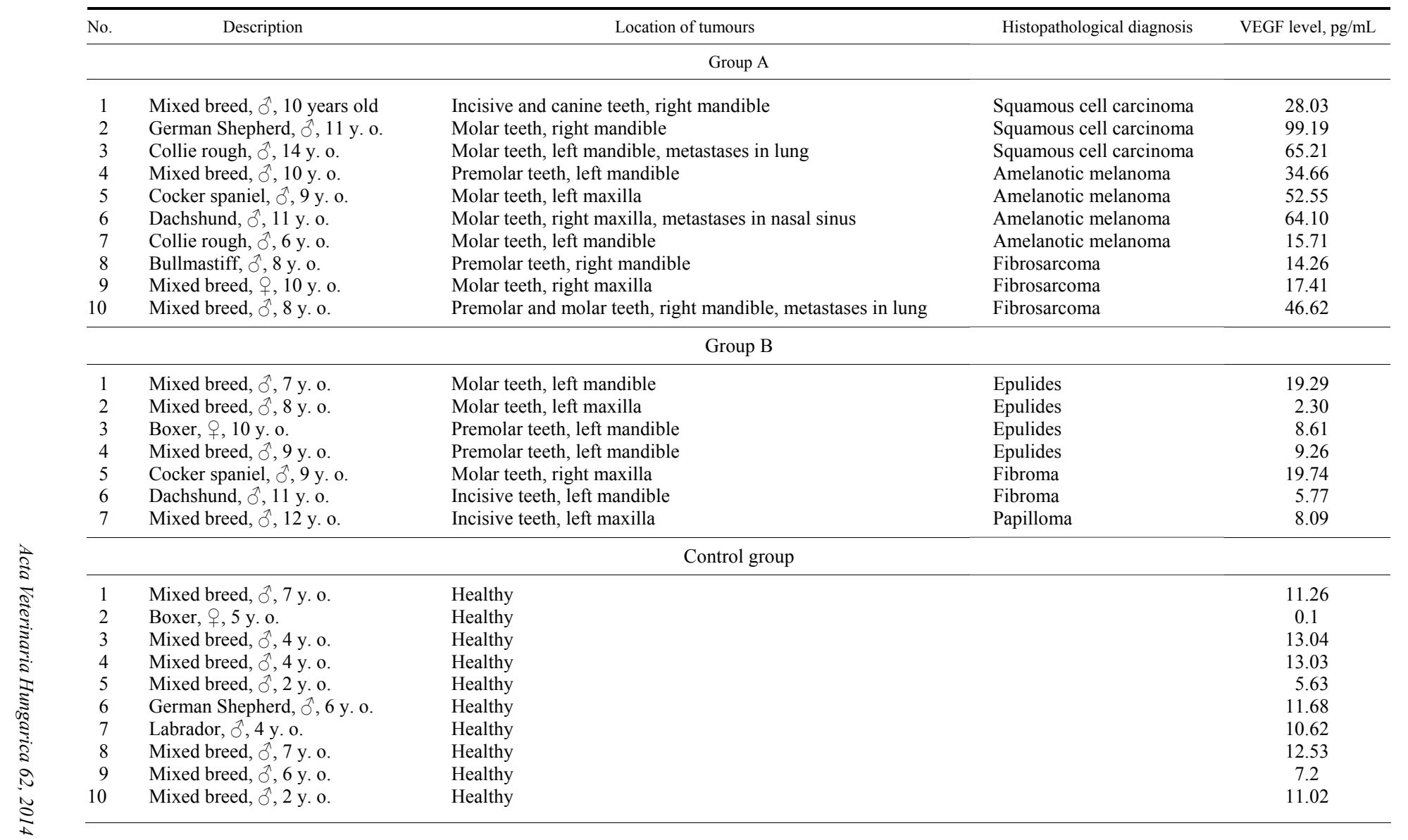


The control group comprised 10 healthy dogs (mixed breed, Labrador, German Shepherd and Boxer, 9 males and 1 female), aged 2-7 years, which were brought in for neutering.

After surgical extraction of the tumour, the obtained material was delivered to the Department of Pathological Anatomy of the Faculty of Veterinary Medicine at the University of Life Sciences in Lublin. Specimens of tumours were preserved in $10 \%$ buffered formalin for $24 \mathrm{~h}$. The diagnosis was established by the examination of samples stained with haematoxylin and eosin, and the type of tumour was determined according to the applicable WHO classification.

Blood taken from the dogs and from animals of the control group was centrifuged and the obtained serum was frozen at $-75^{\circ} \mathrm{C}$. The level of VEGF in the blood serum was determined by ELISA test (Quantikine Canine Immunoassay, R\&D Systems). Every step of the VEGF determination assay was performed in accordance with the manufacturer's guidelines.

A statistical analysis was carried out to verify any significant correlations between the level of VEGF in the serum of affected animals and in animals of the control group. The Mann-Whitney test was employed to verify the significance of the observed discrepancies between results of the two groups when the variables were not normally distributed.

\section{Results}

Histopathological examinations confirmed the malignant character of 10 tumours, whereas in 7 cases the tumours were found to be benign. Therefore, the study group of animals was divided into two subgroups: Group A included animals diagnosed with malignant tumours: 3 cases of squamous cell carcinoma, 3 cases of fibrosarcoma, and 4 cases of amelanotic melanoma. The second subgroup (Group B) included animals diagnosed with benign tumours, i.e. epulides, fibromas and papillomas. The detailed results are presented in Table 1.

The median concentration of VEGF in the serum of dogs diagnosed with malignant tumours of the oral cavity (Group A) was $40.64 \mathrm{pg} / \mathrm{mL}$ [14.26$99.19 \mathrm{pg} / \mathrm{mL}$. The lowest value of $14.26 \mathrm{pg} / \mathrm{mL}$ was observed in the blood serum of animals suffering from fibrosarcomas, while the highest $(99.19 \mathrm{pg} / \mathrm{mL})$ in that of dogs diagnosed with squamous cell carcinoma (Table 1). In the case of melanomas, the serum levels of VEGF ranged between 15.71 and $64.10 \mathrm{pg} / \mathrm{mL}$. In the case of benign tumours, the observed blood serum levels of VEGF were lower and ranged between 2.30 and $19.74 \mathrm{pg} / \mathrm{mL}$ (the detailed results are presented in Table 1). In the control group, the recorded VEGF levels were between 0.1 and $13 \mathrm{pg} / \mathrm{mL}$. The median was $11.14 \mathrm{pg} / \mathrm{mL}$ (Table 2).

A statistically significant elevation of serum VEGF levels was observed in animals suffering from malignant tumours (Group A), compared with the control 
group $(\mathrm{P}<0.001)$ and with dogs diagnosed with benign tumours (Group $\mathrm{B}$; $\mathrm{P}<$ $0.01)$. The results obtained for dogs of Group B did not significantly differ from those of the control group $(\mathrm{P}>0.05)$. The detailed results are presented in Table 2 .

Table 2

Comparison of VEGF characteristics with those of the control group

\begin{tabular}{|c|c|c|c|c|c|}
\hline Group & $\begin{array}{l}\text { Median VEGF } \\
\quad(\mathrm{pg} / \mathrm{mL})\end{array}$ & $\begin{array}{l}\text { Min. VEGF } \\
(\mathrm{pg} / \mathrm{mL})\end{array}$ & $\begin{array}{l}\text { Max. VEGF } \\
\quad(\mathrm{pg} / \mathrm{mL})\end{array}$ & $\begin{array}{c}\text { SD } \\
\text { VEGF }\end{array}$ & $\mathrm{n}$ \\
\hline Group A & 40.64 & 14.26 & 99.19 & 27.31 & 10 \\
\hline Control group & 11.14 & 0.1 & 13.04 & 4.13 & 10 \\
\hline \multicolumn{6}{|c|}{$Z=3.78\left(^{* * *}\right) \mathrm{P}<0.001$} \\
\hline Group B & 8.61 & 2.30 & 19.74 & 6.62 & 7 \\
\hline Control group & 11.14 & 0.1 & 13.04 & 4.13 & 10 \\
\hline \multicolumn{6}{|c|}{$Z=0.29(-) P>0.05$} \\
\hline Group A & 40.64 & 14.26 & 99.19 & 27.31 & 10 \\
\hline Group B & 8.61 & 2.30 & 19.74 & 6.62 & 7 \\
\hline \multicolumn{6}{|c|}{$\mathrm{Z}=2.83\left(^{* *}\right) \mathrm{P}<0.01$} \\
\hline
\end{tabular}

\section{Discussion}

The risk factors influencing the development of neoplastic lesions of the oral cavity include increased exposure to harmful environmental factors and chronic inflammatory state of the periodontium. Lesions are located mainly on the gums, soft palate, tongue and buccal mucosa (Sobczyńska-Rak et al., 2009).

In histopathological preparations taken from the neoplasms, three types of malignant neoplasms were recognised: malignant melanoma, squamous cell carcinoma and fibrosarcoma. According to data of the literature, these are the most often diagnosed malignant tumours of the oral cavity in dogs (Bergman, 2007; Sapierzyński et al., 2007; Sobczyńska-Rak et al., 2009). These tumours often infiltrate the oral mucosa and muscles of the splanchnocranium. In advanced stages, metastases to cranial bones, local lymph nodes and lungs are present.

The formation of blood vessels in a tumour is considered to be a condition of neoplastic progression (Bałan and Słotwiński, 2008; Szala, 2009).

Comparative studies have been conducted to analyse the chemical structure of VEGF in humans and animals. It has been demonstrated that the amino acid sequences in the areas responsible for receptor binding are identical in humans and animals (Scheidegger et al., 1999; Mohammed et al., 2002).

Attempts have been made to determine VEGF in the blood serum in dogs with spontaneously occurring tumours with the use of a human ELISA test which 
indicated $80-90 \%$ of tumours manifested morphologically. The mean VEGF level observed with various types of malignant tumours was between $7.2 \mathrm{pg} / \mathrm{mL}$ and $12.6 \mathrm{pg} / \mathrm{mL}$ in oral melanoma, whereas in the case of benign tumours the value was significantly lower $(0.9-1.3 \mathrm{pg} / \mathrm{mL}$ ) (Wergin and Kaser-Hotz, 2004; Wergin et al., 2006). Meanwhile, Troy et al. (2006), when studying VEGF in dogs suffering from malignant tumours, obtained results between $2.5 \mathrm{pg} / \mathrm{mL}$ and as high as $274 \mathrm{pg} / \mathrm{mL}$. Also, Kato et al. (2007) tested VEGF using a Human VEGF Quantikine ELISA Kit. They confirmed elevation of VEGF levels in the blood serum of dogs diagnosed with malignant mammary gland tumours, with the recorded values ranging from not detectable to $992.9 \mathrm{pg} / \mathrm{mL}$.

In our own research performed with the use of the Canine VEGF Quantikine ELISA Kit, which has been available for several years now, different results were obtained. The mean VEGF concentration in the blood serum of dogs diagnosed with malignant tumours ranged between 14.26 and $65.21 \mathrm{pg} / \mathrm{mL}$, whereas in dogs with benign tumours the values were between 2.30 and $19.74 \mathrm{pg} / \mathrm{mL}$. Evidently, despite the significant homology of human and canine VEGF, considerable discrepancies can be observed between the respective results, which strongly suggests that in order to standardise the results of scientific studies, species-specific assays should always be used.

The increased expression of VEGF, as mRNA in neoplastic tissue as well as the protein itself in plasma, serum or urine, has been observed in many types of neoplastic disease in humans, including cancer of the colon, stomach, breast, lung, prostate, kidney, and urinary bladder (Sobczyńska-Rak, 2012). The increased level of VEGF often correlates with angiogenesis and the presence of metastases. In some neoplasms, e.g. leukaemia, the level of growth factor correlates with a shorter survival time and a lower probability of full remission (Łojko and Komarnicki, 2004; Wąsik-Szczepanek and Koczkodaj, 2008).

It has been shown that angiogenesis plays an essential role in the development of melanomas in humans. Higher levels of VEGF in the serum occur in patients with an advanced neoplastic process and are indicative of a negative prognosis and shorter periods of remission and, according to several authors' contention, they can have a certain prognostic value (Ugurel et al., 2001; Ascierto et al., 2004; Mackiewicz and Kwinta, 2010).

It has been shown that the growth factor is present not only in neoplastic cells but also in stromal cells of a tumour and is, to a large extent, responsible for the uncontrolled growth and the formation of metastases (Smith et al., 2000; Mărgăritescu et al., 2009). As a result of the research, evaluation of the expression of VEGF and its receptors was demonstrated to be a reliable prognostic factor in squamous cell carcinoma of the oral cavity and tongue in humans, as well as in those of the oral cavity and nasal epithelium in dogs. Owing to this, the development and local recurrence as well as the formation of distant metastases can be monitored (Smith et al., 2000; López de Cicco et al., 2004; Shiomitsu et al., 2009). 
Understanding the distribution and role of VEGF in the progression of squamous cell carcinoma of the oral cavity is a key to planning new therapeutic strategies (Mărgăritescu et al., 2009).

From the clinician's perspective the crucial observation was whether the excised lesions were of benign or malignant character. This determination was performed on the basis of haematoxylin and eosin (HE) staining and the tumour type was categorised in accordance with the WHO classification (Head et al., 2003). The study may have been supplemented by additional determination of the proliferation ability (grade, Ki67, mitotic activity), but such tests were not performed under the described research regime as the objective of the study was to determine the blood serum VEGF levels in animals diagnosed with malignant tumours and to relate them to those observed in animals diagnosed with benign tumours and in healthy animals.

In our own research, increased VEGF expression in comparison with the control group was observed in all malignant neoplasms of the oral cavity. The results were statistically significant. On analysing the results, it can be hypothesised that VEGF plays a significant role in the angiogenesis of oral cavity tumours in dogs. It can be assumed that the level of VEGF in the blood serum of affected animals can prove to be a viable indicator in assessing the malignancy of tumours and the prognosis.

Investigating VEGF levels in particular types of malignant tumours and tumours of different characteristics will require further studies to be performed on a larger group of animals suffering from a specific type of cancer, e.g. squamous carcinoma with varying levels of histopathological malignancy. In such a research the proliferation ability (grade, Ki67, mitotic activity) would likely play a more vital role in determining the correlation between serum VEGF level and different characteristics of the given type of tumour. Moreover, changes in VEGF concentrations in a given type of tumour may in the future constitute one of the main prognostic factors which will allow us to determine the animal's predicted life expectancy, but this will require a further, extensive study.

When analysed against the clinical picture of a neoplastic process, VEGF overexpression can influence the choice of the methods of surgical treatment and indicate the likelihood of its effectiveness. Antiangiogenic therapies with the use of monoclonal antibodies against VEGF or substances blocking its receptors seem to be promising, and clinical research in this direction is currently carried out on a large scale globally (Dvorak, 2002; Volk et al., 2008; Szala, 2009; Mackiewicz and Kwinta, 2010). 


\section{References}

Ascierto, P. A., Leonardi, E., Ottaiano, A., Napolitano, M., Scala, S. and Castello, G. (2004): Prognostic value of serum VEGF in melanoma patients: pilot study. Anticancer Res. 24, 4255-4258.

Bałan, B. J. and Słotwiński, R. (2008): VEGF and tumor angiogenesis. Centr. Eur. J. Immunol. 33, 232-236.

Bergman, P. J. (2007): Canine oral melanoma. Clin. Tech. Small. Anim. Pract. 22, 55-60.

Dvorak, H. F. (2002): Vascular permeability factor/vascular endothelial growth factor: a critical cytokine in tumor angiogenesis and potential target for diagnosis and therapy. J. Clin. Oncol. 20, 4368-4380.

Dvorak, H. F., Nagy, J. A., Dvorak, J. T. and Dvorak, A. M. (1988): Identification and characterization of the blond vessels of solid tumors that are leaky to circulating macromolecules. Am. J. Pathol. 133, 95-109.

Ferrara, N. (1999): Molecular and biological properties of Vascular Endothelial Growth Factor. J. Mol. Med. 77, 527-543.

Head, K. W., Cullen, J. M., Dubielzig, R. R., Else, R. W., Misdorp, W., Patnaik, A. K., Tateyama, S. and Van der Gaab, I. (2003): Histologic Classification of the Tumors of the Alimentary System of Domestic Animals. Armed Forces Institute of Pathology in co-operation with the American Registry of Pathology and the World Health Organization Collaborating Center for Worldwide Reference on Comparative Oncology, Washington, 2nd series. ISBN 1-881041-86-7. $257 \mathrm{pp}$.

Iruela-Arispe, M. L. (2008): Endothelial cell activation. In: Figg, W. D. and Folkman, J. (eds) Angiogenesis. An Integrative Approach From Science to Medicine. Springer, New York. pp. $135-143$.

Kato, Y., Asano, K., Mogi, T., Kutara, K., Teshima, K., Edamura, K., Tsumagari, S., Hasegawa, A. and Tanaka, S. (2007): Clinical significance of circulating vascular endothelial growth factor in dogs with mammary gland tumors. J. Vet. Med. Sci. 69, 77-80.

Łojko, A. and Komarnicki, M. (2004): Vascular endothelial growth factor in tumor angiogenesis. Współcz. Onkol. 8, 1-4.

López de Cicco, R., Watson, J. C., Bassi, D. E., Litwin, S. and Klein-Szanto, A. J. (2004): Simultaneous expression of furin and Vascular Endothelial Growth Factor in human oral tongue squamous cell carcinoma progression. Clin. Cancer Res. 10, 4480-4488.

Mohammed, S. I., Bennett, P. F., Craig, B. A., Glickman, N. W., Mutsaers, A. J., Snyder, P. W., Widmer, W. R., De Gortari, A. E., Bonney, P. L. and Knapp, D. W. (2002): Effects of the cyclooxygenase inhibitor, piroxicam, on tumor response, apoptosis, and angiogenesis in a canine model of human invasive urinary bladder cancer. Cancer Res. 62, 356-358.

Mackiewicz, J. and Kwinta, Ł. (2010): New targeted therapies in the treatment of patients with metastatic melanoma. Współcz. Onkol. 14, 15-22.

Mărgăritescu, C., Pirici, D., Simionescu, C., Mogoantă, L., Raica, M., Stîngă, A., Ciurea, R., Stepan, A., Stîngă, A. and Ribatti, D. (2009): VEGF and VEGFRs expression in oral squamous cell carcinoma. Rom. J. Morphol. Embryol. 50, 527-548.

Michailidon, E. Z., Markopoulos, A. K. and Antoniades, D. Z. (2008): Mast cell and angiogenesis in oral malignant and premalignant lesions. Open. Dent. J. 2, 126-132.

Polverini, P. J. (2002): Angiogenesis in health and disease: Insights into basic mechanisms and therapeutic opportunities. J. Dent. Educ. 8, 962-975.

Rawlings, N. G., Simko, E., Bebchuk, T., Caldwell, S. J. and Singh, B. (2003): Localization of integrin alpha(v)beta3 and vascular endothelial growth factor receptor-2 (KDR/Flk-1) in cutaneous and oral melanomas of dog. Histol. Histopathol. 3, 819-826.

Roselli, M., Mineo, T. C., Basili, S., Mariotti, S., Martini, F., Bellotti, A., Ambrogi, V., Spila, A., D’Alessandro, R., Gazzaniga, P. P., Guadagni, F. and Ferroni, P. (2003): Vascular endo- 
thelial growth factor (VEGF-A) plasma levels in non-small cell lung cancer: relationship with coagulation and platelet activation markers. J. Thromb. Haemost. 89, 177-184.

Sacewicz, I., Wiktorska, M., Wysocki, T. and Niewiarowska, J. (2009): Mechanisms of cancer angiogenesis. Postepy Hig. Med. Dosw. 63, 159-168.

Sapierzyński, R., Malicka, E., Bielecki, W., Krawiec, M., Osińska, B., Sendecka, H. and SobczakFilipiak, M. (2007): Oral tumors in dogs and cats: retrospective review of 143 cases. Medycyna Wet. 63, 1196-1199.

Scheidegger, P., Weiglhofer, W., Suarez, S., Kaser-Hotz, B., Steiner, R., Ballmer-Hofer, K. and Jaussi, R. (1999): Vascular endothelial growth factor (VEGF) and its receptors in tumorbearing dogs. Biol. Chem. 380, 1449-1454.

Shiomitsu, K., Johnson, C. L., Malarkey, D. E., Pruitt, A. F. and Thrall, D. E. (2009): Expression of epidermal growth factor receptor and vascular endothelial growth factor in malignant canine epithelial nasal tumours. Vet. Comp. Oncol. 7, 106-114.

Smedley, R. C., Spangler, W. L., Esplin, D. G., Kitchell, B. E., Bergman, P. J., Ho, H. Y., Bergin, I. L. and Kiupel, M. (2011): Prognostic markers for canine melanocytic neoplasms: a comparative review of the literature and goals for future investigation. Vet. Pathol. 48, 54-72.

Smith, B. D., Smith, G. L., Carter, D., Sasaki, C. T. and Haffty, B. G. (2000): Prognostic significance of vascular endothelial growth factor protein levels in oral and oropharyngeal squamous cell carcinoma. J. Clin. Oncol. 18, 2046-2052.

Sobczyńska-Rak, A. (2012): The role of VEGF in process of neovasculogenesis. In: Ran, S. (ed.) Tumor Angiogenesis. Intech, Rijeka, Croatia. pp. 181-196.

Sobczyńska-Rak, A., Polkowska, I., Śmiech, A. and Sobolewska, E. (2009): Angiogenesis in malignant oral-cavity tumours in dogs. Bull. Vet. Inst. Pulawy 53, 463-466.

Szala, S. (2009): Angiogenesis and immune suppression: yin and yang of tumor progression? Postepy Hig. Med. Dosw. 63, 598-612.

Takahashi, H. and Shibuya, M. (2005): The vascular endothelial growth factor (VEGF)/VEGF receptor system and its role under physiological and pathological conditions. Clin. Sci. 109, $227-241$.

Taylor, K. H., Smith, A. N., Higginbotham, M., Schwartz, D. D., Carpenter, D. M. and Whitley, E. M. (2007): Expression of vascular endothelial growth factor in canine oral malignant melanoma. Vet. Comp. Oncol. 5, 208-218.

Troy, G. C., Panciera, D., Lanz, O., Robertson, J. L. and Ward, D. L. (2006): Endostatin and Vascular Endothelial Growth Factor concentrations in healthy dogs, dogs with selected neoplasia, and dogs with nonneoplastic diseases. J. Vet. Intern. Med. 20, 144-150.

Uchida, N., Nagai, K., Sakurada, Y. and Shirota, K. (2008): Distribution of VEGF and flt-1 in the normal dog tissues. J. Vet. Med. Sci. 70, 1273-1276.

Ugurel, S., Rappl, G., Tilgen, W. and Reinhold, U. (2001): Increased serum concentration of angiogenic factors in malignant melanoma patients correlates with tumor progression and survival. J. Clin. Oncol. 19, 577-583.

Volk, L. D., Flister, M. J., Bivens, Ch. M., Stutzman, A., Desai, N., Trieu, V. and Ran, S. (2008): Nab-paclitaxel efficacy in the orthotopic model of human breast cancer is significantly enhanced by concurrent anti-Vascular Endothelial Growth Factor A therapy. Neoplasia 10, 613-623.

Wąsik-Szczepanek, E. and Koczkodaj, D. (2008): Vascular endothelial growth factor (VEGF) and its role in B-cell chronic lymphocytic leukemia. Acta Haematol. Pol. 39, 197-205.

Wergin, M. C. and Kaser-Hotz, B. (2004): Plasma Vascular Endothelial Growth Factor (VEGF) measured in seventy dogs with spontaneously occurring tumours. In Vivo 18, 15-20.

Wergin, M. C., Roos, M., Inteeworn, N., Laluhovà, D., Allemann, K. and Kaser-Hotz, B. (2006): The influence of fractionated radiation therapy on plasma vascular endothelial growth factor (VEGF) concentration in dogs with spontaneous tumors and its impact on outcome. Radiother. Oncol. 2, 239-244. 